\title{
Does parents' socio-economic status matter in intentions of vaccinating against human papillomavirus for adolescent daughters?
}

\author{
Frank Pan ${ }^{1}$, Hui-Gan Shu ${ }^{2}$
}

1. Tajen University, Medical Tourism Research Center

2. Kaohsiung Veteran General Hospital, Pingtung Branch, Department of Laboratory

\begin{abstract}
Background: The Human Papilloma Virus (HPV) vaccination provides substantial protection, and it is best to be taken before the age of twelve. Taiwan approved HPV vaccines since 2006. However, very few female adolescent have been vaccinated until now.

Objectives: To examine whether the parents' socio-economic status matters in deciding to purchase HPV vaccination for their daughters based on the theory of planned behavior.

Method: A structured questionnaire to collect 394 responses from parents of adolescent girls in Taiwan. Data was coded to categorize relevant socio-economic classes, and was analyzed with SPSS.

Results: The behavior intentions of parents with low (mean= 5.28) and high (5.01) socio-economic status are significantly stronger than the moderate (4.56) in deciding to purchase the HPV vaccination. Socio-economic factor has a slightly negative impact $(B=-0.08)$, and attitude $(0.68)$, subjective norms $(0.16)$, and behavior control $(0.32)$ have positive impacts on the parents' intention.

Conclusion: Major impacts on the decision to purchase an HPV vaccination for their adolescent was not due to the parents' socio-economic status but the parent's attitude. As the major predictor of a less complicated decision, attitudes toward the HPV vaccination should be reinforced through continuous communications between service providers and patient-advocate groups.
\end{abstract}

Keywords: Human Papillomavirus, cervical cancer, theory of planned behavior, vaccination, adolescent DOI: http://dx.doi.org/10.4314/ahs.v15i1.4

\section{Introduction}

Cervical cancer is the highest threat to the health and lives of women worldwide. It has been estimated that 380,000 new cases were identified each year during the last ten years, and roughly 230,000 women died in one year ${ }^{1}$. The World Health Organization (WHO) has suggested vaccinating Human Papillomavirus (HPV) beyond the traditional Pap Smear for at-risk women ${ }^{2}$. Evidence from the literature indicates that cervical cancer vaccination can provide at least five years of protection for at-risk women.

\section{Corresponding author: \\ Frank Pan \\ Tajen University, Medical Tourism \\ Research Center \\ 20, Weixin Rd., Yampu, Pingtung, \\ Taiwan 907 (R. O. C.), \\ Tel: 886-8-7624002 \#3120, \\ E-mail: frankpan@tajen.edu.tw}

It is an especially effective measure for females before their first sexual intercourse, roughly at the age of the 7 th grade or 12 years old ${ }^{4,5,6}$. In Taiwan, cervical cancer is the second highest cause of death for women, next to breast cancer ${ }^{7}$. Several HPV vaccinations have been approved and launched since 2006, yet the expense is not reimbursed by the compulsory National Health Insurance Policy ${ }^{8}$. Since the HPV vaccination service is expensive in Taiwan, some studies suggest that the price levels significantly affect the parents' intentions. Despite the fact that the current market price is around 12,000 NTD (about 400 USD), an acceptable price would be around 500 NTD (about 17 USD) as the ceiling ${ }^{8}$. Given that the societal barrier is the most challenging factor in implementing P4 medical practices (predictive, preventive, personalized and participatory $)^{9,10}$, this research aims to explore whether or not the parents'socio-economic status will affect their decisions to purchase this vaccination service for their young teenagers, in the absence of a government subsidy. 


\section{Cervical Cancers}

Human Papillomavirus (HPV) is the most common virus found in the victims of cervical cancers ${ }^{11}$, particularly for those women between the ages of 35 and $45^{12}$, who were of low socio-economic status, had $\mathrm{E}$ levels, and were cigarette smokers, among other factors $^{12}$

The Pap Smear has long been used as a reliable tool to detect cervical cancers in the early stage. This procedure may help patients and physicians to start an effective treatment with good levels of survival. However, to be complete in protecting women's health, an advanced preventive protection treatment is needed before the organ is attacked. HPV vaccination is, thus, suggested as the best approach for preventing this disease ${ }^{13}$

\section{HPV vaccines}

The HPV vaccine effectively prevents women from being attacked by $\mathrm{HPV}^{6,14}$, in particular the HPV16/18; The theory assumes that behavior intention is the major as a result, they may be effectively free from major and immediate determinant of a targeted behavior. In cervical cancers that are caused by $\mathrm{HPV}^{11,15}$. In the TPB, behavior intention represents the probability 2006, the Federal Food and Drug Administration of a person to perform the target behavior and that it (FDA) of the United States (US) firstly approved can be predicted by attitudes (AT), social norms (SN), the Gardasil vaccine (a quadrevalent vaccine for HPV and perceived behavioral control (PBC). Attitude re$6 / 11 / 16 / 18$ ) to be used in females between 9 and 26 fers to one's judgment of a behavior as bad or good. years $^{16}$. The Taiwan government also approved Gar- Subjective norm means someone's perception of the dasil and Cervarix (a divalent vaccine) in 2006 and rules that exist in their social network. The term 2008, respectively.

Clinical evidence indicated both quadrivalent and divalent vaccines provide superior protection. perceived behavior control is used to scale a person's perception of their ability to accomplish the target behavior. The current research takes the TPB as the theoretical basis.

Figure 1 Research Framework and Results

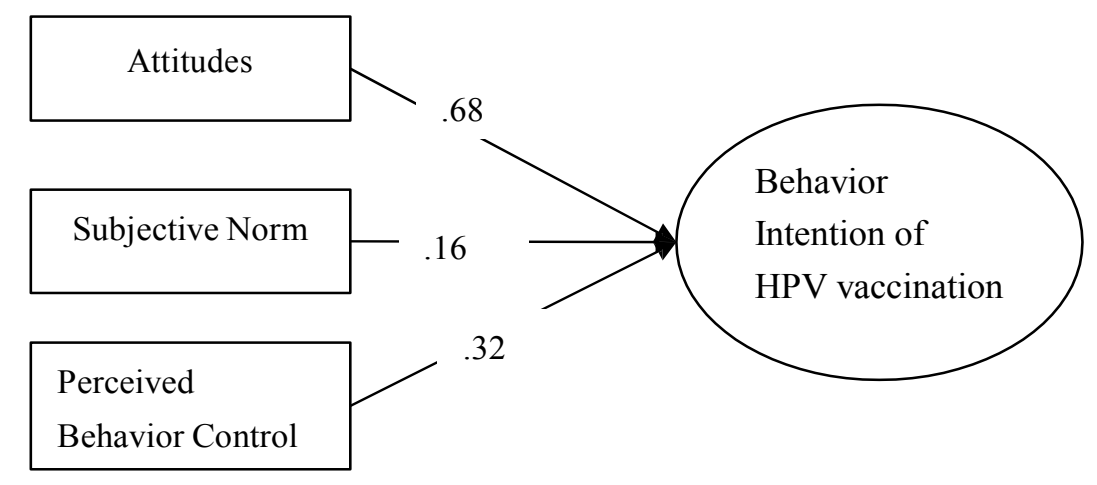

Source: Ajzen, I. (1989). Attitude Structure and Behavior, In A. Pratkanis, A.R., Breckler, S.J. and A. G. Greenwald, A.G. (Eds.). Attitude structure and function, Hillsdale. N.J.: Erlbaum \&Associates, 252.
Given that the socio-economic factor may affect an ty were selected to reflect the distribution of tribes and individual's attitude toward and the perceptions of social norms, as the social cognition theories ${ }^{23}$ generally suggest, this research examines whether o not the social and economic status of the parents of the teenage girls can affect their intentions to accept a HPV vaccination ${ }^{25}$

The research questions of this research thus included "Do the parents' intentions differ according to the income levels, occupations, and education?" "Does socio-economic status create differences in deciding to get HPV vaccination?"

Hypotheses to be tested were as follows:

H1-1: Parents' intention to purchase the HPV vaccination will vary from one educational level to another. H1-2: Parents' intention to purchase the HPV vac cination will vary across different occupations.

H1-3: Parents' intention to purchase the HPV vaccination will vary across different socio-economic statuses.

H2: Parents' attitude, subjective norm, and perceived behavior control can positively affect their intentions to purchase HPV vaccination services for their adolescent girls.

\section{Material and Method}

\section{Instruments}

As suggested by Ajzen (2006) ${ }^{24}$, we amended the wordings of the questionnaire to be consistent with the research context. The questionnaire was sent to some academic and medical experts for verification. The questionnaire contained major constructs of the theory of planned behavior, as well as the respondents' demographic factors, such as gender, income levels, education levels, marital status, and types of occupation. The instrument has good reliability at 0.892 of Cronbach's $\alpha$

\section{Samples and analytic process}

This research investigated the students' parents, since like many other medical treatments, the decision for such a medical vaccination decision was typically made by the parents, rather than by the adolescents, ${ }^{1}$ ${ }^{24}$. Six schools suggested by the local education authori-
The population sample was 2709 (32.57\% members of the entire Pingtung area of 15268 people). Samples were randomly selected from $25 \%$ of the female students at the school (two schools provided $33 \%$ due to their small size), i.e., one out of four, based on the student ID. The minimum sample size from each school was 30. As a result, 677 question-

naires were distributed to the students' parents (either a parent or a fiduciary guardian) through the students' class teachers of 49 classes; of those, 510 were returned for a $75.35 \%$ response rate. A data cleaning process was then performed, and 116 questionnaires were deleted after cross-checks of the reverse question. This measure further ensured the survey was free from the problem of common method variance statistical techniques, such as descriptive and, Oneway ANOVA, followed by Scheffe's or LSD (Fisher's Least Significant Difference) for post hoc analysis, cross-tabulation, and regression analysis to reveal valuable insights.

\section{Data analysis and results}

\section{Samples Characteristic}

Table 1 shows how the samples gathered were distributed.

The discussion of the sample distribution is presented in a later section. Female comprised the major group of parental respondents with 362 responses or $91.9 \%$. Slightly over half $(52 \%)$ of the respondents were beween ages 41-50, and around $85 \%$ were between ages $31-50$. The average age was roughly 43.45 years old. This denotes that the parents' ages when their teenage girls were born were between ages 28-38, with an average age of 31 years old. This is consistent with the national status, despite that some of extra-ordinary cases when their births may have occurred earlier or later. Education levels properly reflect the current status by showing that nearly $90 \%$ of the parents possessed at least a high school diploma, with an average education of 12 years. This means the parents should have had good knowledge of health matters, including of vaccines. Classes with a smaller sample (i.e. $\mathrm{n}<30$ ) were then integrated into the proximate one to gain a new and meaningful class for further analysis, as shown in Table 1 shows. (CMV). Data was analyzed using SPSS with several 


\section{Table 1 Sample distribution}

\begin{tabular}{|c|c|c|c|}
\hline \multirow[t]{2}{*}{ Variables } & \multirow[t]{2}{*}{ Categories } & \multicolumn{2}{|c|}{ Re-categorized } \\
\hline & & $\mathrm{n}$ & $\%$ \\
\hline Gender & $\begin{array}{l}\text { Male } \\
\text { Female }\end{array}$ & 362 & $\begin{array}{r}81.12 \\
91.88\end{array}$ \\
\hline \multirow[t]{2}{*}{ Marriage } & Married & 343 & 87.06 \\
\hline & Divorced \&Widow & 51 & 12.94 \\
\hline \multirow[t]{3}{*}{ Age } & $31-40$ & 128 & 32.49 \\
\hline & $41-50$ & 205 & 52.03 \\
\hline & $\begin{array}{l}51+ \\
\text { average }=43.45\end{array}$ & 61 & 15.48 \\
\hline \multirow[t]{3}{*}{ Education } & Junior & 46 & 11.68 \\
\hline & High school & 256 & 64.97 \\
\hline & $\begin{array}{l}\text { College } \\
\text { average }=12.49\end{array}$ & 92 & 23.35 \\
\hline \multirow{5}{*}{${ }^{1}$ Income (NTD, or 0.0.03USD) } & 20,000 & 136 & 34.52 \\
\hline & $20,001-40,000$ & 117 & 29.70 \\
\hline & $40,001-60,000$ & 83 & 21.07 \\
\hline & 60,001 & 58 & 14.72 \\
\hline & Average $=35,559$ NTD. & & \\
\hline \multirow{4}{*}{ 'Occupation } & General labor & 90 & 22.84 \\
\hline & Employer & 30 & 7.61 \\
\hline & State employee / Medicine & 83 & 21.07 \\
\hline & Housewife / Retired & 191 & 48.48 \\
\hline \multirow{3}{*}{${ }^{2}$ SE Status } & 1 Low $(1 \sim 2)$ & 129 & 32.74 \\
\hline & 2 Middle(3 6) & 180 & 45.69 \\
\hline & $3 \operatorname{High}(8 \sim 12)$ & 85 & 21.57 \\
\hline
\end{tabular}

$\mathrm{N}=394 ; 1 \mathrm{NTD}=0.03 \mathrm{USD}$

1 General labor is the category representing employee to any private business contrast to the state employee. Medicine jobs are generally less turnover and better compensation. 2. Socio-economic status is the products of education and income. SE classes are classified based on the sample distribution.

Variations of Theory of Planned Behavior Con- that represents the majority of the market.

\section{tructs by Demographic Factors}

We then examined the behavior intention (BI) using Occupation. Parents who were retired or whos varied levels of the respondents' demographic factors. role was that of a housewife (or a house husband) BI denotes the probability of a person accepting or were far more willing to have their girls receive the performing the target item or behavior. HPV vaccination than any other types of occupation. It is interesting to note that the parents who worked as Education. HPV vaccination intentions varied ac- general labor (i.e., blue collar) comprised the group cording to educational levels. As expected, the parents least likely to receive the HPV vaccination, includwith a college education and above were more likely ing their intentions, attitude, subjective norms and than their high school graduate counterparts to have perceived behavior control. It is also worthy note that their girls receive HPV vaccination. Table 2, ironically, state employees are generally characterized with stable shows that parents with only a high school educa- and better compensation, and healthcare professiontion have less intent than those parents with junior or als are generally more knowledgeable about health primary educations. Similar forms of comparison are protections and disease prevention. Yet this research also found attitudes toward HPV vaccination, in has shown that both state employers and healthcare subjective norms, and in perceived behavior control. employees appear to have a weaker willingness (mean This means that promotions for HPV vaccination $=4.71$, s. d. $=1.16$ ) than most other occupations (e.g., can more easily reach the highly educated parents and mean $=5.18, \mathrm{~s} . \mathrm{d} .=1.15$ for housewives and retired) achieve the promotions' goals. However, although the except but those in the general labor workforce. Fiparents who are high school -educated may require nally, it is interesting to note that the strongest intenmore efforts to be persuaded to use this vaccination tion is found in the housewives (or househusbands) service, they are, in the meantime, the largest group and retired persons groups.

Socio-economic status. The middle range in so- 1.36 ) is inferior to class 1 (mean $=5.28$, s. d. $=1.15$ ) cio-economic status seems to be the most problematic and to class 3 (mean $=5.01, \mathrm{~s} . \mathrm{d}$. $=1.18$ ), from their group of respondents for HPV vaccination promo- intention to their behavioral control of all theory of tions. As Table 4 shows, class 2 (mean $=4.56$, s. d. $=$ planned behavior $(\mathrm{TPB})$ constructs.

Table 2 Analysis of education, occupation, and socio-economic status on intentions

\begin{tabular}{|c|c|c|c|c|c|c|c|c|}
\hline Variables & Cat. & $\mathrm{n}$ & Mean & SD & $\mathrm{F}$ & Sig. & Scheffe's & LSD \\
\hline \multirow[t]{3}{*}{ Education $^{a}$} & 1 & 46 & 5.18 & .82 & $4.070^{*}$ & .018 & & $1>2$ \\
\hline & 2 & 256 & 4.76 & 1.40 & & & & $3>2$ \\
\hline & 3 & 92 & 5.12 & 1.10 & & & & \\
\hline \multirow[t]{4}{*}{ Occupation ${ }^{b}$} & 1 & 90 & 4.34 & 1.46 & $10.746^{* * *}$ & .000 & $2>1,4>3$, & \\
\hline & 2 & 30 & 5.23 & 1.35 & & & $4>1$ & \\
\hline & 3 & 83 & 4.71 & 1.16 & & & & \\
\hline & 4 & 191 & 5.18 & 1.15 & & & & \\
\hline & 1 & 129 & 5.28 & 1.15 & $12.597^{* * *}$ & .000 & $1>2,3>2$ & \\
\hline \multirow{2}{*}{ status ${ }^{{ }^{c}}$} & 2 & 180 & 4.56 & 1.36 & & & & \\
\hline & 3 & 85 & 5.01 & 1.18 & & & & \\
\hline
\end{tabular}

a. 1. Junior and lower, 2.High school, 3.College and above.

a. 1.General labor, 2. Business owner, 3. State employee \& Medicine, 4. Housewife \& retired.

c. 1. Low, 2. Middle, 3. High.

\section{Test results}

As a result of the analysis, hypotheses $1-1,1-2$, and 1-3 support the assertion that intentions are significantly different across different education levels, occupations, and socio-economic status, as shown in table 2

A cross-tabulation analysis and a hierarchical regresion were performed to reveal the associalions of theory of planned behavior (TPB) constructs and socio-economic status. Parents with low and high socio-economic status showed high intent mean $=5.28$,

Table 3 Cross-tabulation of intentions and socio-economic status

\begin{tabular}{lrrrrr}
\hline \multirow{2}{*}{ Socio-economic } & Intentions & Low & Moderate & High & Sum \\
\hline Low & $\mathrm{n}$ & 16 & 79 & 34 & 129 \\
\multirow{2}{*}{ Moderate } & $\%$ & $12.4 \%$ & $61.2 \%$ & $26.4 \%$ & $100.0 \%$ \\
\multirow{3}{*}{ High } & $\mathrm{n}$ & 67 & 84 & 29 & 180 \\
& $\%$ & $37.2 \%$ & $46.7 \%$ & $16.1 \%$ & $100.0 \%$ \\
Sum & $\mathrm{n}$ & 22 & 42 & 21 & 85 \\
& $\%$ & $25.9 \%$ & $49.4 \%$ & $24.7 \%$ & $100.0 \%$ \\
& $\mathrm{n}$ & 105 & 205 & 84 & 394 \\
$x^{2}=24.886, d f=4, p=0.000<0.05$ & & & & &
\end{tabular}

$x^{2}=24.886, d f=4, p=0.000<0.05$
5.01 in table 2 respectively) to purchase the HPV vaccination noteworthy that the moderate categohad a comparatively weak intention (mean $=4.56$ ), as Table 3 shows, of which where $\mathrm{x} 2=24.886, \mathrm{df}=4$, $p=0.000<0.05$. The socio-economic status appears to have a negative impact on the intention. In general, attitude is the best predictor among TPB variables for intention, followed by perceived behavioral control (PBC) and subjective norm, shown as model 2 in table 
Table 4 Summary of regression analysis

\begin{tabular}{lcccc}
\hline & Model 1 & $\mathrm{t}$ & Model 2 & $\mathrm{t}$ \\
\hline Constant & 5.25 & $29.17^{* * *}$ & -0.50 & $-4.38^{* * *}$ \\
Socio-economic & -0.19 & $-2.14^{*}$ & -0.08 & $-2.89^{* * *}$ \\
AT & & & 0.68 & $16.81^{* * *}$ \\
SN & & & 0.16 & $3.05^{* * *}$ \\
PBC & & & 0.32 & $6.14^{* * *}$ \\
$R$ & .107 & & .948 & \\
$R^{2}$ & .012 & & .899 & \\
\hline
\end{tabular}

\section{Discussion}

HPV vaccinating, may hold a conservative attitude The parents in this research were substantially well ed- toward this disease prevention method, were exposed ucated and, thus, were expected to be amenable to the to less positive information regarding HPV vaccinaconcepts of disease prevention and health protection. tion, and appear to have weaker confidence in this However, the magnitudes of behavioral intentions, new disease prevention approach. Unfortunately, class along with the preceding variables, were not aligned 2 with scores of 3 to 6 , is neither low in education no with the educational levels. It is notable that the less in income. To gain a score of 3 , a respondent needs to educated parents, i.e., those with only a junior school be located in at least the one third level in either eduor primary education, had stronger intentions to have cation (college or above) or income $(40,000 \sim 60,000)$ their girls vaccinated. Parents with better education Since college education level not correlated with havwere expected to be more willing to accept the ing good intention levels, this means that the income captioned <?> vaccination, since they may have levels again contribute to the major part of this inferio had much better opportunities to accumulate health ranking. Intentions are not aligned with income levels. knowledge than their less educated counterparts.

However, the research test results provided a differ- Recognizing the importance of HPV vaccination in ent conclusion by showing no significant difference. Behavior intentions also opposed expected directions in terms of other personal demographic factors, as gender, age, income, and occupation. Noteworthy are the healthcare professionals.

They were expected to be more aware of the need for disease prevention, e.g., the HPV vaccines for cervical cancers in this research, and to give a positive response. We conducted several personal interviews with some of the respondents in the study to further enquire the reasons for their responses. The vaccination's expense was the major drawback. The reason that the highest score of intention to vaccinate went to those parents who were housewives (husbands) and retired, was may be due to them being the major healthcare decision makers for the entire family. A wide distribution of health education and continuous public health promotion programs in the past decade may have also significantly equalized the knowledge of disease prevention and health protection.

It is logical to infer that parents who were either low in income or low in education were reluctant to accept protecting the health of a female citizens, and the relatively high price of such a service, some county governments that, are generally wealthier, have launched free vaccinations to the qualified girls. This may impose a huge pressure on the central government to provide free services as part of national health policy in the near future. However, a free offer program may not guarantee full participation, as the lessons have shown from unsatisfactory participation rates for free cancer scanning for years.

Research suggests that free cancer screening an health promotion programs are significantly affected by the participants' attitudes, subjective norms, and perceived behavior control. This may be also applicable to the HPV vaccination ${ }^{19-22}$

Whether or not the expenses are borne by the government or by the beneficiary, the success of this program would greatly depend on how health and educational professionals motivate the parents.
Although Ajzen ${ }^{26}$ has argued that the effects of independent variables may be varied in different contexts (i.e., types of behavior), the meta-analysis performed by McEachan and colleague 18 have suggested that perceived behavioral control $(\mathrm{PBC})$ is the major predictor for health- associated behavior. The current research gains a different result to show that the $\mathrm{PBC}$ is a predictor second only to attitude. A possible reason behind this is the parents' perception of vaccinations.

In general, a vaccination is simple and easily accessible, and the respondents should have acquired sufficient knowledge on the nature of this particular service (except some new immigrants). This has made this issue more a 'why' or 'what' question rather than a 'how'. People may wonder why a HPV vaccination is needed, instead of how or where to receive it. Another possible reason may go to the comprehensive coverage of Taiwan's National Health Insurance Policy. Beyond paying for the majority of medical expenses, the government offers free disease screening programs and some free vaccination services for infants, school children, and aged citizens. As a result, people ma take health protection or disease prevention projects for granted; this may explain why respondents of in this research are reluctant to pay for a HPV vaccination. People may perceive that the HPV vaccination should also be offered free to citizens. The fact is that the $\mathrm{HPV}$ vaccines are expensive and may not be affordable by the NHIB in the near future, since the health budget of the country is already highly squeezed by the social benefits of some minor-advocacyte groups, such as the aged and handicapped.

\section{Conclusions}

Behavior intentions and its preceding factors varied along with different socio-economic levels, as the literature generally agreed ${ }^{18}$, yet the correlation is not linear. Parents in this research appear to strongly accept the HPV vaccination for their teenage girls, no matter how they differ in education, occupation, and socio-economic status.

Inconsistent with previous studies, this research reveals that attitude is the major predictor of behavior, rather than perceived additional lights on our understanding of the role that attitude can play as a variable in a theory of planned behavior (TPB) model. Given that vaccinations are popular in many countries, people have been well-edu- cated about the safety and effectiveness of such preentive medicine. It is a decision that does not involve complicated information. The research study results thus lead to the conclusion that attitude will be the major predictor of a behavior that requires a less complicated decision- making process. In practice, no matter who will be responsible for the payment, a promotional program that continuously persuades adolescents' parents about the need for this vaccine, and an effective method that facilitates communications between service providers and patient-advocate groups are essential ${ }^{9}$. Programs of this kind should focus on enhancing the parents' knowledge or and attitudes toward cervical cancers and the HPV vaccine as a remedy through continuous communications.

\section{References}

. World Health Organization (2010). Are the number of cancer cases increasing or decreasing in the world? Retrieved October 10, 2013 from http://www. who.int/features/qa/15/en/index.htm

Frazer IH. Prevention of cervical cancer through papillomavirus vaccination. Nature Rev Immun, 2004 4(1): 46-55.

3. Raley TC, Followwill KA, Zimet GD, Ault KA. Gynecologists' attitudes regarding human papilloma virus vaccination: A survey of fellows of American College of Obstetricians and Gynecologists. Infect Dis Obs Gyne, 2004; 12(3-4): 127-133.

4. Davis K, Dickman E, Ferris D, Dias JK. Human papillomavirus vaccine acceptability among parents of 10- to 15-year-old adolescents. J Lower Genital Tract Dis, 2004; 8(3), 188-194.

5. Harper DM, Franco EL, Wheeler C, Ferri DG, Jenkins D, Schuind A, et al.. Efficacy of a bivalent $\mathrm{L} 1$ virus-like particle vaccine in prevention of infection with human papillomavirus types 16 and 18 in young women: A randomised controlled trial. Lancet, 2004; 364: 1757-1765.

. Paavonen J, Jenkins D, Bosch FX, Naud P, Salmeron J, Wheeler CM, et al. Efficacy of a prophylactic adjuvanted bivalent L1 virus-like-particle vaccine against infection with human papillomavirus types 16 and 18 in young women: An interim analysis of a phase III double-blind, randomized controlled trail. Lancet, 2007; 369: 2161-2170

. National Health Insurance Bureau. Statistics on National Health. 2010. Retrieved at October 25, 2013 
from http://www.nhi.gov.tw/webdata/webdata.asp? menu=1\&menu_id $=4 \&$ webdata_id $=2516 \& W D$ $\mathrm{ID}=471$.

8. Lee CC, Lee TSH, Chen TS, Lu YM, Lin X. Factors associated with women intention of the human papillomavirus vaccination study in Kinmen. Heal Promot \& Heal Edu J, 2010; 30: 1-16.

9. Hood L, Friend SH. Predictive, personalized, preventive, participatory (P4) cancer medicine. Nature Rev Clinic Onc, 2011; 8(3), 184-187.

10. Younesi E, Hofmann-Apitius M. From integrative disease modeling to predictive, preventive, personalized and participatory (P4) medicine. EPMA J, 2013; 4(1): 23.

11. Walboomers JM, Jacobs MV, Manos MM, Bosch FX, Kummer JA, Shah KV, Snijders PJ, Peto J, Meijer CJ, Muñoz N. Human papillomavirus is a necessary cause of invasive cervical cancer worldwide. $J$ Path, 1999; 189(1): 1-3.

12. Morice P, Castaigne D. Advances in the surgical management of invasive cervical cancer. Obs \& Gyn, 2005; 17: 5-12.

13. Eduardo LF, Diane MH. Vaccination against human papillomavirus infection: a new paradigm in cervical cancer control. Vaccine, 2005; 23: 2388-2394.

14. Frazer IH, Cox J. Finding a vaccine for human papillomavirus. Lancet, 2006; 367(9528): 2058-2059.

15. Smith JS, Lindsay L, Hoots B, Keys J, Franceschi S, Winer R, Clifford GM. Human papillomavirus type distribution in invasive cervical cancer and high-grade cervical lesions: A meta-analysis update. Int J Cancer, 2007: 121(3): 621-632.

16. Daley EM, Vamos CA, Buhi ER, Kolar SK, McDermott RJ, Hernandez N, Fuhrmann HJ. Influences on human papillomavirus vaccination status among female college students. J Women's Heal, 2009; 19(10): 1885-1991. DOI: 10.1089=jwh.2009.1861. 17. Lin JW. Factors associated with parental acceptance of adolescent human papillomavirus vaccination. Unpublished dissertation, 2009; China Medical University.
18. McEachan RRC, Conner M, Taylor NJ, Lawton RJ. Prospective prediction of health-related behaviours with the Theory of Planned Behaviour: A meta-analysis. Heal Psycy Rev, 2011; 5(2): 97-144.

19. Juraskova I, O’Brien M, Mullan B, Bari R, Laidsaar-Powell $\mathrm{R}$, McCaffery $\mathrm{K}$. HPV vaccination and the effect of information framing on intentions and behaviour: An application of the theory of planned behaviour and moral norm. Int J Behav Med, 2012; 19(4): 518-525.

20. Hertweck SP, LaJoie AS, Pinto MD, Flamini L, Lynch T, Logsdon MC (2013). Health care decision making by mothers for their adolescent daughters regarding the quadrivalent HPV vaccine. J Pedi Adoles Gynec, 2013; 26(2): 96-101.

21. Hofman R, van Empelen P, Richardus JH, de Kok IMCM, de Koning, HJ, van Ballegooijen M, Korfage IJ. Predictors of HPV vaccination uptake: a longitudinal study among parents. Heal Edu Res, 2014; 29(1): 83-96.

22. Geshnizjani A. Predicting intention to get the HPV vaccine using the underlying behavioral, normative, and control belief constructs of the Theory of Planned Behavior. In 142 ${ }^{\text {nd }}$ APHA Annual Meeting and Exposition (November 15-November 19, 2014). APHA.

23. Fiske ST, Taylor SE. Social cognition: From brains to culture. 2013, Sage.

24. Ajzen I. Constructing a TPB questionnaire: Conceptual and methodological considerations. 2006. Retrieved October 12, 2013, from http://www-unix.oit. umass.edu/ aizen/index.html.

25. Zimet GD, Mays RM, Sturm LA, Ravert AA, Perkins SM, Juliar BE. Parent attitudes about sexually transmitted infection vaccination for their adolescent children. Arch Pediatric Adoles Med, 2005; 159: 132-137.

26. Ajzen I. The theory of planned behavior, Org Behav \& Human Decision Proc, 1991; 50: 179-211. 